\title{
Novel Pharmacologic Approaches to Treating Cannabis Use Disorder
}

\author{
Rebecca E. Balter • Ziva D. Cooper • Margaret Haney
}

Published online: 1 March 2014

(C) Springer International Publishing AG 2014

\begin{abstract}
With large and increasing numbers of people using cannabis, the development of cannabis use disorder (CUD) is a growing public health concern. Despite the success of evidence-based psychosocial therapies, the low rates of initial abstinence and high rates of relapse during and following treatment for CUD suggest a need for adjunct pharmacotherapies. Here we review the literature on medication development for the treatment of CUD, with a particular focus on studies published within the last three years (2010-2013). Studies in both the human laboratory and in the clinic have tested medications with a wide variety of mechanisms. In the laboratory, the following medication strategies have been shown to decrease cannabis withdrawal and selfadministration following a period of abstinence (a model of relapse): the cannabinoid receptor agonist, nabilone, and the adrenergic agonist, lofexidine, alone and in combination with dronabinol (synthetic THC), supporting clinical testing of these medication strategies. Antidepressant, anxiolytic and antipsychotic drugs targeting monoamines (norepinephrine, dopamine, and serotonin) have generally failed to decrease withdrawal symptoms or laboratory measures of relapse. In terms of clinical trials, dronabinol and multiple antidepressants (fluoxetine, venlafaxine and buspirone) have failed to decrease cannabis use. Preliminary results from controlled clinical trials with gabapentin and $\mathrm{N}$-acetylcysteine (NAC) support further research on these medication strategies. Data from open label and laboratory studies suggest that lithium and oxytocin also warrant further testing. Overall, it is likely that different medications will be needed to target distinct aspects of problematic cannabis use: craving, ongoing use,
\end{abstract}

R. E. Balter $\cdot$ Z. D. Cooper $\cdot$ M. Haney $(\bowtie)$

Division on Substance Abuse, Department of Psychiatry, Columbia

University Medical Center, 1051 Riverside Drive, Unit 120, New

York, NY 10032, USA

e-mail:mh235@columbia.edu withdrawal and relapse. Continued research is needed in preclinical, laboratory and clinical settings.

Keywords Marijuana P Pharmacological treatment . Withdrawal $\cdot$ Cannabis use disorder $\cdot$ Dronabinol

\section{Introduction}

In 2012, of the approximately 31.7 million Americans who reported using cannabis at least once, over $13 \%$ (4.3 million people) reported cannabis dependence or abuse. Furthermore, $24 \%$ of the 4 million people admitted for any type of drug treatment reported cannabis as their primary drug, a percentage that has steadily increased over the past decade [1,2]. With the large and increasing number of people using cannabis, the treatment of CUD will continue to be a major public health concern.

CUD is defined in the DSM-5 as a problematic pattern of cannabis use leading to clinically significant impairment or distress occurring within a 12-month period as manifested by cannabinoid tolerance and withdrawal; increasing amounts of cannabis use over time; inability to control consumption; craving; and recurrent cannabis use having negative implications on social, professional and educational life [3]. Withdrawal symptoms usually appear approximately 24 hours after abstinence initiation, peak within two to six days and remit within two weeks [4]. Symptoms may include irritability, anger or aggression; nervousness or anxiety; sleep difficulty (insomnia, disturbing dreams); decreased appetite or weight loss; restlessness; depressed mood; or physical discomforts (abdominal pain, shakiness/tremors, fever, chills or headache) $[5,6,7 \cdot]$. Withdrawal is diagnosed if at least three of these symptoms develop. A week after cessation of use, additional symptoms may appear such as fatigue, yawning, 
difficulty in concentration, and rebound periods of increased appetite or hypersomnia [3].

Currently, psychosocial therapies are the only approaches indicated for addressing CUD. The results from over 25 years of research demonstrate that these treatments can successfully reduce cannabis use and promote abstinence when compared to control conditions. Cognitive-behavioral therapy (CBT), motivational enhancement therapy (MET), contingency management (CM) and family-based therapies are the most successful of the psychotherapeutic models (for reviews of psychosocial treatments see Budney et al. 2007 and Litt 2013 [8, 9]). Yet despite the significant improvement in outcome with these treatments, nonresponse and relapse rates among patients remain high (about $70 \%$ ). Thus, there is a clear need to improve the efficacy of the current treatment options.

The primary purpose of this article is to review the most recent literature (with a focus on studies published since 2010) on the development of pharmacotherapies to complement psychosocial therapies for CUD (for additional reviews of pharmacological treatments see Vandrey et al. 2009, Weinstein et al. 2011 and Danovitch and Gorelick 2012 [10-12]). Studies, conducted in both clinical and human laboratory settings, have focused on developing medications to help initiate abstinence, reduce withdrawal and prevent relapse. There are currently no FDA-approved pharmacological treatments for this disorder so research is critical in this area.

\section{Agonist Therapy}

To date, drugs across a variety of classes have been studied for the treatment of CUD with various degrees of success. One reasonably successful approach has been with agonist replacement therapies. The use of the nicotine patch for the treatment of tobacco dependence, and the use of methadone or buprenorphine maintenance for opioid dependence, are other examples of such an approach.

The cannabis plant contains over 80 cannabinoid compounds (as defined by their chemical structure), most of which are poorly categorized [13]. Delta 9-tetrahydrocannabinol (THC) is by far the most studied and is the primary psychoactive component of the plant [14]. Oral THC can produce dose-dependent positive subjective effects and feelings of intoxication [15, 16]. Additionally, the 'good drug effect' of smoked cannabis in laboratory studies corresponds to the concentration of THC in the plant $[15,17]$. THC binds to the eponymously named cannabinoid receptors, CB1 and CB2. $\mathrm{CB} 1$ activation is predominately responsible for the psychoactive effects of cannabinoids as the receptors are highly concentrated in brain areas involved in attention, memory, higher cognitive processes, bodily coordination, sensory and time perception, and reinforcement of behavior by drugs, as well as by natural rewards such as food and sex. The $\mathrm{CB} 1$ receptors are also activated by the endogenous cannabinoids: anandamide (AEA) and 2-arachidonoylglycerol (2-AG; see Cooper and Haney 2008 for review of cannabinoid neurobiology [18]).

Initial research investigating the agonist replacement approach for CUD assessed dronabinol (Marinol), an FDAapproved oral formulation of synthetic THC to treat chemotherapy-related nausea and as an appetite stimulant for AIDS wasting syndrome. These predominantly small, withinsubject, placebo-controlled human laboratory studies with non-treatment seeking participants are designed to assess medication effects on clinically-relevant behaviors, such as cannabis self-administration, withdrawal symptoms, cognitive performance, sleep, food intake and cannabis intoxication [19]. Two such studies found that 50 to $60 \mathrm{mg}$ /day dronabinol produced a reduction in a range of withdrawal symptoms while producing mild intoxication at higher doses [20, 21]. Both Budney et al. (2007) and Vandrey et al. (2013) have replicated the effects of dronabinol on withdrawal and demonstrated dose-dependant attenuation of symptoms (30 to $120 \mathrm{mg}$ /day) [22, 23]. Yet daily dronabinol administration did not reduce cannabis self-administration or relapse, defined in the laboratory as cannabis self-administration following a period of abstinence [21, 24].

A single, moderate dose of dronabinol (40 mg/day), in combination with behavioral therapies, has been tested in a randomized, placebo-controlled, double-blind, 12-week trial [25•]. Although cannabis use decreased over the course of the trial, there was no significant difference between dronabinoltreated and placebo-treated groups in the degree of reduction. However, dronabinol-treated participants did have higher treatment retention $(77 \%)$ compared to placebo-treated participants $(61 \%)$, and had significantly fewer withdrawal symptoms. Of note, the reduction in withdrawal in the absence of changes in cannabis use replicated the laboratory study findings, providing support for the predictive validity of the laboratory models. Thus, dronabinol monotherapy was not shown to be efficacious for reducing cannabis use or engendering abstinence, despite significantly reducing symptoms of withdrawal.

Recently, findings from a laboratory study with nabilone, a synthetic THC analogue also FDA-approved to treat nausea, suggest that this medication shows considerable promise as a potential treatment for CUD. Nabilone (6 or $8 \mathrm{mg} /$ day) significantly reversed cannabis withdrawal-induced irritability, sleep disruption and anorexia. Unlike dronabinol, nabilone also reduced a laboratory measure of cannabis relapse [26•]. Nabilone may be superior to dronabinol because it has better bioavailability ( $>60 \%$ vs. $<20 \%$ ) resulting in more consistent, dose-related behavioral effects across individuals. Nabilone also has a longer duration of action than dronabinol ( $>6$ hours vs. 4 hours), so patients may only need to take medication once or twice per day [27]. Finally, unlike dronabinol, nabilone produces urinary metabolites distinct 
from those of cannabis, which allows clinicians or researchers to confirm whether patients are taking their medication and whether they are continuing to smoke cannabis [28]. Overall, these behavioral and pharmacological data clearly support clinical testing of nabilone for CUD.

An alternative to using exogenous cannabinoid agonists as a potential treatment for CUD is to increase cannabinoid signaling by modulating the endogenous endocannabinoids, AEA and 2-AG. This can be accomplished pharmacologically by inhibiting the enzymes responsible for their degradation, fatty acid amide hydrolase (FAAH) and monoacylglycerol lipase (MGAL). In mice, acute administration of both FAAH and MGAL inhibitors were able to significantly attenuate antagonist-precipitated THC-withdrawal signs, lending support to the potential of this approach [29]. There are no published data on the use of FAAH or MGAL inhibitors to treat cannabis dependence in humans, although a clinical study at the Yale School of Medicine is currently under way with a FAAH inhibitor (NCT01618656).

Finally there is considerable scientific interest in cannabidiol (CBD), a non-psychoactive cannabinoid found in low concentrations of most cannabis strains, as a potential treatment for cannabis dependence. One case report described the treatment of a cannabis-dependent patient with 300 to $600 \mathrm{mg} /$ day of cannabidiol for 11 days [30]. The individual reported a reduction in withdrawal symptoms during treatment and a reduction in cannabis use six months after treatment, compared to baseline. Placebo-controlled studies are needed to confirm this finding. A double blind, placebocontrolled, randomized trial was recently completed with nabiximols (Sativex; GW Pharmaceuticals, UK), a buccal spray with an approximately $1: 1$ ratio of cannabidiol and THC [31]. Cannabis-dependent individuals were treated with nabiximols (maximum dose of $86.4 \mathrm{mg}$ THC, $80 \mathrm{mg} \mathrm{CBD/}$ day) during a six-day inpatient phase. Nabiximols significantly decreased withdrawal symptoms and modestly increased study retention compared to placebo, but did not decrease cannabis use or time to relapse during the follow up phase (28 days). These results are consistent with those evaluating the effects of dronabinol alone, so the contribution of cannabidiol to the study outcome is not clear [25•]. Longerterm outpatient testing of nabiximols, and placebo-controlled clinical trials with cannabidiol alone, are still needed.

Additionally, research is still needed to confirm the site, or sites, of action of cannabidiol. Although it has very low binding affinity for either the CB1 or CB2 cannabinoid receptor, cannabidiol can increase endocannabinoid signaling by inhibiting FAAH [32-34]. In fact, a study in schizophrenic patients treated with cannabidiol ( $800 \mathrm{mg}$ /day) demonstrated elevated plasma anandamide levels that correlated with antipsychotic response [35]. A recent in vitro study suggested that cannabidiol could also inhibit the function of nicotinic acetylcholine receptors [36]. This is particularly interesting considering that compounds that decrease alpha 7-nACh receptor activity reduced the reinforcing effects of cannabinoid agonists in rats and squirrel monkeys [37]. Thus, there are several potential mechanisms by which cannabidiol may be a useful treatment for cannabis use disorder, but human laboratory and clinical data are needed.

\section{Antagonist Therapies}

Directly decreasing the subjective and reinforcing effects of abused drugs via antagonist administration provides an alternative approach to treating problematic cannabis use. A reduction in positive drug effects could facilitate disruption of ongoing drug use, aiding in the initiation of abstinence. This theory has proved effective in the treatment of opioid dependence with the use of the opiate antagonist, naltrexone [38]. Initial laboratory studies with the CB1 receptor antagonist, rimonabant, found that acute antagonist administration reduced subjective and cardiovascular effects of cannabis [39, 40]. Unfortunately the use of rimonabant is no longer clinically feasible due to psychiatric side effects (anxiety, depression and suicidality) during clinical trials testing of its use for the treatment of obesity [41]. These psychiatric side effects may reflect rimonabant's inverse agonist properties [42]. If so, it is possible that a neutral antagonist would block the cannabinoid receptor without altering intrinsic endocannabinoid activity, and may attenuate the reinforcing effects of cannabis without producing the adverse effects of rimonabant.

Another approach to decreasing the reinforcing effects of cannabis is through modulation of the endogenous opioid system. There is extensive evidence of a bidirectional interaction between the endogenous cannabinoid and opioid systems including receptor co-localization in the CNS [43, 44]. Preclinical data show that acute opioid antagonist pre-treatment reduces cannabinoid self-administration [45-47]. Human laboratory studies demonstrate that while acute oral naltrexone increases the positive subjective effects of cannabis in daily users [48], repeated naltrexone administration shows an opposite pattern of effects, and may have potential as an adjunct pharmacological treatment for CUD [49].

\section{Non-cannabinoid Approaches}

A number of studies have assessed the potential utility of antidepressants, anxiolytics and antipsychotics for the treatment of cannabis dependence. These medications are of interest because of their ability to potentially address specific withdrawal symptoms (e.g., anxiety, irritability) or to treat other substance use disorders. For example, the antidepressant mirtazapine, a norepinephrine and serotonin modulator, given in combination with psychotherapy has been shown to reduce 
depression and anxiety during alcohol detoxification, compared to psychotherapy alone [50]. In the laboratory, mirtazapine $(30 \mathrm{mg} /$ day for 14 days) reversed cannabis withdrawal-related disruptions in food intake and sleep, but did not reduce the mood symptoms of withdrawal and did not decrease laboratory measures of cannabis relapse [51]. Escitalopram (10 mg/day for 9 weeks), a selective serotonin reuptake inhibitor, also failed to decrease depression or anxiety during cannabis withdrawal, or to increase rates of abstinence in a double-blind, placebo-controlled clinical study [52]. Finally, a randomized, placebo-controlled, 12-week, clinical trial was done with buspirone $(60 \mathrm{mg} /$ day $)$, a partial serotonin receptor antagonist typically used as an anxiolytic. The trial reported no significant effect on anxiety, withdrawal or craving compared to placebo; patients also dropped out at a relatively high rate $(\sim 50 \%)$ [53].

Two double-blind, placebo-controlled, 12-week trials have assessed antidepressants in individuals with co-morbid CUD and depression. In adolescents, the selective serotonin reuptake inhibitor fluoxetine ( 10 to $20 \mathrm{mg} /$ day) failed to have a significant effect on either depression or drug-use outcomes [54]. In adults, venlafaxine ( $375 \mathrm{mg} /$ day), a serotoninnorepinephrine reuptake inhibitor, also failed to reduce measures of depression, and increased cannabis use compared to placebo [55].

Lofexidine, currently used to treat opiate withdrawal in Europe, is an alpha 2-adrenergic receptor agonist that reduces noradrenergic cell activity. In a laboratory study, lofexidine $(2.4 \mathrm{mg} /$ day for 7 days) was able to reduce cannabis withdrawalinduced chills, gastrointestinal complications and restlessness, and to increase sleep. Even more promising, lofexidine in combination with dronabinol produced more wide-ranging improvements in mood and craving during withdrawal, and attenuated cannabis relapse in the laboratory [21]. An ongoing clinical trial, at the New York State Psychiatric Institute, is evaluating the ability of lofexidine, in combination with dronabinol, to reduce cannabis use and withdrawal in treatment seeking, cannabis-dependent patients (NCT01020019).

Chronic cannabis use is also associated with reduced levels of both gamma-aminobutyric acid (GABA) and glutamate throughout the cingulate cortex, which suggests that these systems may also provide potential pharmacological targets [56]. A drug discrimination study demonstrated that the $\mathrm{GABA}_{\mathrm{B}}$ agonist baclofen substituted for THC, providing support for the role of the GABA receptor in the physiological effects of cannabis [57]. However, baclofen (60 or $90 \mathrm{mg} /$ day, 16 days) did not show promise in a human laboratory study of cannabis withdrawal and relapse. Although baclofen dosedependently decreased cannabis craving, it worsened cognitive performance and did not decrease cannabis relapse [51]. The $\mathrm{GABA}_{\mathrm{A}}$ agonist zolpidem, by contrast, attenuated sleep disruption during cannabis withdrawal, supporting further study of this medication for treating CUD [58].
Gabapentin, an antiepileptic and analgesic for neuropathic pain, is another promising drug. Although a GABA analogue, gabapentin does not bind to the GABA receptors [59]. Instead, gabapentin seems to act predominately at voltage-gated calcium channels and normalizes levels of corticotrophin releasing factor (CRF) and downstream GABA activity [60]. CRF signaling is known to play a role in the induction of opiate withdrawal symptoms and could potentially play a role in cannabis withdrawal as well [61]. Gabapentin's effects in cannabis-dependent volunteers were assessed in a 12-week, randomized, double-blind, placebo-controlled, pilot clinical trial [62]. Although there was a high drop-out rate (72\%), gabapentin $(1,200 \mathrm{mg} /$ day $)$ significantly attenuated withdrawal severity and reduced cannabis use compared to placebo. This proof-of-concept study supports continued research on gabapentin. To this end, a clinical trial of gabapentin for the treatment of CUD is being conducted at Scripps Research Institute (NCT00974376).

$N$-acetylcysteine (NAC) is an over-the-counter supplement that up-regulates the cystine-glutamate exchanger and is hypothesized to restore normal glutamate activity disrupted by chronic drug use [63, 64]. In an eight-week, double-blind, randomized, placebo-controlled trial, cannabis-dependent adolescents received NAC (1,200 mg, twice daily) in combination with contingency management. Those receiving NAC had more than twice the odds of having THC-negative urine test results during treatment compared with those receiving contingency management alone [65]. A multi-site trial of NAC for the treatment of CUD in adults is currently underway (NCT01675661).

Antipsychotics have also been tested in laboratory models of cannabis withdrawal and relapse. Quetiapine, an atypical antipsychotic that acts as an antagonist at the dopamine, serotonin and norepinephrine receptors, was tested because of its potential to improve sleep, increase appetite and decrease anxiety during cannabis withdrawal [66, 67]. Although quetiapine decreased some withdrawal symptoms as predicted (sleep disruption, appetite loss and anxiety), it increased both cannabis craving and relapse in the laboratory, lessening enthusiasm for its potential to treat CUD [68].

Two, small, open-label studies reported moderate utility of lithium in reducing cannabis withdrawal symptoms, although the toxicity of lithium at high doses is always of concern [69, 70]. Though the mechanism of action of lithium is not fully understood, a preclinical study suggests that lithium might attenuate cannabis withdrawal symptoms by increasing levels of oxytocin [71]. A recent study found that oxytocin, administered intra-nasally to cannabis smokers, reduced both subjective measures of cannabis craving and anxiety following stress [72]. These data support investigation of oxytocin administration to attenuate symptoms of cannabis withdrawal. 


\section{Conclusions}

As research on pharmacological treatments for CUD continues, a few key findings are of note. First, cannabinoid agonists (nabilone, dronabinol in combination with lofexidine, and lofexidine alone), were the only drugs that decreased drug-taking in a human laboratory model of relapse, supporting the notion that agonist replacement and attenuation of noradrenergic activity show promise for relapse prevention. Although dronabinol alone failed to clinically reduce cannabis use, a higher dose might have been more effective. Further, that study was designed to evaluate the initiation of abstinence; dronabinol or the more bioavailable agonist nabilone, might have greater utility in the prevention of relapse [25•]. These studies also support further testing of lofexidine in combination with other drugs, and generally illustrate the utility that can be gained from combining medications.

Second, gabapentin and NAC were the only drugs tested in placebo-controlled clinical trials that decreased cannabis use (abstinence induction). Third, the ability of a drug to reduce cannabis withdrawal symptoms is not predictive of its ability to alter drug-taking behaviors (reduce use or prevent relapse). However, all the studies that reported positive changes in drug use also reported a reduction in withdrawal during early abstinence, suggesting that this feature is an important component of an efficacious medication.

In general, this most recent set of studies demonstrates that additional research at every stage of problematic cannabis use is needed to facilitate abstinence initiation and to prevent relapse. Looking forward, it will be important to acknowledge co-morbid substance use disorders as both potential and necessary treatment targets. For example, Haney et al. (2013) found that current cigarette smoking is a robust predictor of cannabis relapse in the laboratory and a potential target for intervention [73]. Proper treatment of co-morbid psychiatric disorders will likely play a critical role in the successful treatment of cannabis use disorder. With the changing legal landscape in the USA, it seems that the number of people who use cannabis, and thus the number who develop problematic use, may rapidly grow. Consequently, it is clear that continued research to develop safe and effective pharmacotherapies is critical.

\section{Compliance with Ethics Guidelines}

Conflict of Interest Rebecca E. Balter, Ziva D. Cooper, and Margaret Haney declare that they have no conflict of interest.

Human and Animal Rights and Informed Consent This article does not contain any studies with human or animal subjects performed by any of the authors.

\section{References}

Papers of particular interest, published recently, have been highlighted as:

- Of importance

1. Substance Abuse and Mental Health Services Administration, results from the 2012 national survey on drug use and health: summary of national findings, NSDUH series H-46, HHS publication no. (SMA) 13-4795. Rockville: Substance Abuse and Mental Health Services Administration, 2013.

2. Substance Abuse and Mental Health Services Administration, Center for Behavioral Health Statistics and Quality. Treatment episode data set (TEDS): 2001-2011. National Admissions to Substance Abuse Treatment Services. BHSIS Series S-65, HHS Publication No. (SMA) 13-4772. Rockville: Substance Abuse and Mental Health Services Administration, 2013.

3. American Psychiatric Association. Diagnostic and statistical manual of mental disorders (DSM-5). Arlington: American Psychiatric Publishing; 2013.

4. Budney AJ, Hughes JR, Moore BA, Vandrey R. Review of the validity and significance of cannabis withdrawal syndrome. Am J Psychiatry. 2004;161(11):1967-77.

5. Haney M, Ward AS, Comer SD, Foltin RW, Fischman MW. Abstinence symptoms following smoked marijuana in humans. Psychopharmacology (Berlin). 1999;141(4):395-404.

6. Budney AJ, Hughes JR, Moore BA, Novy PL. Marijuana abstinence effects in marijuana smokers maintained in their home environment. Arch Gen Psychiatry. 2001;58(10):917-24.

7. - Allsop DJ, Norberg MM, Copeland J, Fu S, Budney AJ. The cannabis withdrawal scale development: patterns and predictors of cannabis withdrawal and distress. Drug Alcohol Depend. 2011;119: 123-9. A study proposing a cannabis withdrawal scale to quantify the presence and severity of withdrawal for clinical and research purposes.

8. Budney AJ, Roffman R, Stephens RS, Walker D. Marijuana dependence and its treatment. Addict Sci Clin Pract. 2007;4(1):4-16.

9. Litt MD, Kadden RM, Petry NM. Behavioral treatment for marijuana dependence: randomized trial of contingency management and self-efficacy enhancement. Addict Behav. 2013;38(3):1764 75 .

10. Vandrey R, Haney M. Pharmacotherapy for cannabis dependence: how close are we? CNS Drugs. 2009;23(7):543-53.

11. Weinstein AM, Gorelick DA. Pharmacological treatment of cannabis dependence. Curr Pharm Des. 2011;17(14):1351-8.

12. Danovitch I, Gorelick DA. State of the art treatments for cannabis dependence. Psychiatr Clin N Am. 2012;35(2):30926.

13. Turner CE, Elsohly MA, Boeren EG. Constituents of Cannabis sativa L. XVII. A review of the natural constituents. J Nat Prod. 1980;43(2):169-234.

14. Felder CC, Glass M. Cannabinoid receptors and their endogenous agonists. Annu Rev Pharmacol Toxicol. 1998;38:179200.

15. Hart CL, Ward AS, Haney M, Comer SD, Foltin RW, Fischman MW. Comparison of smoked marijuana and oral delta (9)-tetrahydrocannabinol in humans. Psychopharmacology (Berlin). 2002;164(4):407-15.

16. Haney M, Gunderson EW, Rabkin J, Hart CL, Vosburg SK, Comer $\mathrm{SD}$, et al. Dronabinol and marijuana in HIV-positive marijuana smokers. Caloric intake, mood, and sleep. J Acquir Immune Defic Syndr. 2007;45(5):545-54. 
17. Haney M. Effects of smoked marijuana in healthy and HIV+ marijuana smokers. J Clin Pharmacol. 2002;42(11 Suppl):34S-40.

18. Cooper ZD, Haney M. Cannabis reinforcement and dependence: role of the cannabinoid CB1 receptor. Addict Biol. 2008;13(2): 188-95.

19. Haney M. Self-administration of cocaine, cannabis and heroin in the human laboratory: benefits and pitfalls. Addict Biol. 2009;14(1):9-21.

20. Haney M, Hart CL, Vosburg SK, Nasser J, Bennett A, Zubaran C, et al. Marijuana withdrawal in humans: effects of oral THC or divalproex. Neuropsychopharmacology. 2004;29(1):158-70.

21. Haney M, Hart CL, Vosburg SK, Comer SD, Reed SC, Foltin RW. Effects of THC and lofexidine in a human laboratory model of marijuana withdrawal and relapse. Psychopharmacology (Berlin). 2008;197(1):157-68.

22. Budney AJ, Vandrey RG, Hughes JR, Moore BA, Bahrenburg B. Oral delta-9-tetrahydrocannabinol suppresses cannabis withdrawal symptoms. Drug Alcohol Depend. 2007;86(1):22-9.

23. Vandrey R, Stitzer ML, Mintzer MZ, Huestis MA, Murray JA, Lee D. The dose effects of short-term dronabinol (oral THC) maintenance in daily cannabis users. Drug Alcohol Depend. 2013;128(12):64-70.

24. Hart CL, Haney M, Ward AS, Fischman MW, Foltin RW. Effects of oral THC maintenance on smoked marijuana self-administration. Drug Alcohol Depend. 2002;67(3):301-9.

25. - Levin FR, Mariani JJ, Brooks DJ, Pavlicova M, Cheng W, Nunes EV. Dronabinol for the treatment of cannabis dependence: a randomized, double-blind, placebo-controlled trial. Drug Alcohol Depend. 2011;116(1-3):142-50. This is a large, well-designed, clinical trial of synthetic THC, dronabinol (40 mg/day) in combination with behavioral therapies for the treatment of cannabis dependence. The study found that dronabinol decreased withdrawal symptoms (as had been previously shown in laboratory studies) and increased study retention but did not increase abstinence.

26. - Haney M, Cooper ZD, Bedi G, Vosburg SK, Comer SD, Foltin RW. Nabilone decreases marijuana withdrawal and a laboratory measure of marijuana relapse. Neuropsychopharmacology. 2013;38(8):1557-65. A recent and promising laboratory study reporting that the THC analogue nabilone (6-8 $\mathrm{mg} /$ day) was able to reduce both marijuana withdrawal symptoms and relapse at doses that do not produce intoxication. These data strongly support further clinical testing.

27. Bedi G, Cooper ZD, Haney M. Subjective, cognitive and cardiovascular dose-effect profile of nabilone and dronabinol in marijuana smokers. Addict Biol. 2013;18(5):872-81.

28. Fraser $A D$, Meatherall $R$. Lack of interference by nabilone in the EMIT d.a.u. cannabinoid assay, Abbott TDx cannabinoid assay, and a sensitive TLC assay for delta 9-THC-carboxylic acid. J Anal Toxicol. 1989;13(4):240.

29. Schlosburg JE, Carlson BL, Ramesh D, Abdullah RA, Long JZ, Cravatt BF, et al. Inhibitors of endocannabinoid-metabolizing enzymes reduce precipitated withdrawal responses in THC-dependent mice. AAPS J. 2009;11(2):342-52.

30. Crippa JA, Hallak JE, Machado-de-Sousa JP, Queiroz RH, Bergamaschi M, Chagas MH, et al. Cannabidiol for the treatment of cannabis withdrawal syndrome: a case report. J Clin Pharm Ther. 2013;38(2):162-4.

31. Allsop DJ, Copeland J, Lintzeris N, Dunlop AJ, Montebello M, Sadler C, et al. (2013) A randomized controlled trial of nabiximols (Sativex ${ }^{\mathbb{R}}$ ) as an agonist replacement therapy during cannabis withdrawal. JAMA Psychiatry. In Press.

32. Mechoulam R, Peters M, Murillo-Rodriguez E, Hanus LO. Cannabidiol—recent advances. Chem Biodivers. 2007;4(8):167892.

33. Bisogno T, Hanus L, De Petrocellis L, Tchilibon S, Ponde DE, Brandi I, et al. Molecular targets for cannabidiol and its synthetic analogues: effect on vanilloid VR1 receptors and on the cellular uptake and enzymatic hydrolysis of anandamide. Br J Pharmacol. 2001;134(4):845-52.

34. Campos AC, de Paula SV, Carvalho MC, Ferreira FR, Vicente MA, Brandão ML, et al. Involvement of serotonin-mediated neurotransmission in the dorsal periaqueductal gray matter on cannabidiol chronic effects in panic-like responses in rats. Psychopharmacology (Berlin). 2013;226(1):13-24.

35. Leweke FM, Piomelli D, Pahlisch F, Muhl D, Gerth CW, Hoyer C, et al. Cannabidiol enhances anandamide signaling and alleviates psychotic symptoms of schizophrenia. Trans1 Psychiatry. 2012;2: e94.

36. Mahgoub M, Keun-Hang SY, Sydorenko V, Ashoor A, Kabbani N, Al Kury L, et al. Effects of cannabidiol on the function of $\alpha 7$ nicotinic acetylcholine receptors. Eur J Pharmacol. 2013;720(1-3): 310-9.

37. Justinova Z, Mascia P, Wu HQ, Secci ME, Redhi GH, Panlilio LV, et al. Reducing cannabinoid abuse and preventing relapse by enhancing endogenous brain levels of kynurenic acid. Nat Neurosci. 2013;16(11):1652-61.

38. Comer SD, Sullivan MA, Hulse GK. Sustained-release naltrexone: novel treatment for opioid dependence. Expert Opin Investig Drugs. 2007;16(8):1285-94.

39. Huestis MA, Gorelick DA, Heishman SJ, Preston KL, Nelson RA, Moolchan ET, et al. Blockade of effects of smoked marijuana by the CB1-selective cannabinoid receptor antagonist SR141716. Arch Gen Psychiatry. 2001;58(4):322-8.

40. Huestis MA, Boyd SJ, Heishman SJ, Preston KL, Bonnet D, Le Fur $\mathrm{G}$, et al. Single and multiple doses of rimonabant antagonize acute effects of smoked cannabis in male cannabis users. Psychopharmacology (Berlin). 2007;194(4):505-15.

41. Le Foll B, Gorelick DA, Goldberg SR. The future of endocannabinoid-oriented clinical research after CB1 antagonists. Psychopharmacology (Berlin). 2009;205(1):171-4.

42. Fong TM, Heymsfield SB. Cannabinoid-1 receptor inverse agonists: current understanding of mechanism of action and unanswered questions. Int J Obes (Lond). 2009;33(9):947-55.

43. Robledo P, Berrendero F, Ozaita A, Maldonado R. Advances in the field of cannabinoid — opioid cross-talk. Addict Biol. 2008;13(2): 213-24.

44. Scavone JL, Sterling RC, Van Bockstaele EJ. Cannabinoid and opioid interactions: implications for opiate dependence and withdrawal. Neuroscience. 2013;248:637-54.

45. Braida D, Pozzi M, Parolaro D, Sala M. Intracerebral selfadministration of the cannabinoid receptor agonist CP 55,940 in the rat: interaction with the opioid system. Eur J Pharmacol. 2001;413(2-3):227-34.

46. Navarro M, Carrera MR, Fratta W, Valverde O, Cossu G, Fattore L, et al. Functional interaction between opioid and cannabinoid receptors in drug self-administration. J Neurosci. 2001;21(14):5344-50.

47. Justinova Z, Tanda G, Munzar P, Goldberg SR. The opioid antagonist naltrexone reduces the reinforcing effects of delta 9 tetrahydrocannabinol (THC) in squirrel monkeys. Psychopharmacology (Berlin). 2004;173(1-2):186-94.

48. Cooper ZD, Haney M. Opioid antagonism enhances marijuana's effects in heavy marijuana smokers. Psychopharmacology (Berlin). 2010;211(2):141-8.

49. Haney M, Bedi G, Cooper Z. Chronic naltrexone modulates marijuana's reinforcing, subjective and cardiovascular effects. Neuropsychopharmacology. 2012;38:S346.

50. Liappas J, Paparrigopoulos T, Tzavellas E, Rabavilas A. Mirtazapine and venlafaxine in the management of collateral psychopathology during alcohol detoxification. Prog Neuropsychopharmacol Biol Psychiatry. 2005;29(1):55-60.

51. Haney M, Hart CL, Vosburg SK, Comer SD, Reed SC, Cooper ZD, et al. Effects of baclofen and mirtazapine on a laboratory model of 
marijuana withdrawal and relapse. Psychopharmacology (Berlin). 2010;211(2):233-44.

52. Weinstein AM, Miller H, Bluvstein I, Rapoport E, Schreiber S, BarHamburger R, et al. Treatment of cannabis dependence using escitalopram in combination with cognitive-behavior therapy: a double-blind placebo-controlled study. Am J Drug Alcohol Abuse. 2014;40(1):16-22.

53. McRae-Clark AL, Carter RE, Killeen TK, Carpenter MJ, Wahlquist AE, Simpson SA, et al. A placebo-controlled trial of buspirone for the treatment of marijuana dependence. Drug Alcohol Depend. 2009;105(1-2):132-8.

54. Cornelius JR, Bukstein OG, Douaihy AB, Clark DB, Chung TA, Daley DC, et al. Double-blind fluoxetine trial in comorbid MDDCUD youth and young adults. Drug Alcohol Depend. 2010;112(12):39-45.

55. Levin FR, Mariani J, Brooks DJ, Pavlicova M, Nunes EV, Agosti V, et al. A randomized double-blind, placebo-controlled trial of venlafaxine-extended release for co-occurring cannabis dependence and depressive disorders. Addiction. 2013;108(6):1084-94.

56. Prescot AP, Renshaw PF, Yurgelun-Todd DA. $\gamma$-Amino butyric acid and glutamate abnormalities in adolescent chronic marijuana smokers. Drug Alcohol Depend. 2013;129(3):232-9.

57. Lile JA, Kelly TH, Hays LR. Separate and combined effects of the GABA (B) agonist baclofen and $\triangle 9-\mathrm{THC}$ in humans discriminating $\triangle 9$-THC. Drug Alcohol Depend. 2012;126(1-2):216-23.

58. Vandrey R, Smith MT, McCann UD, Budney AJ, Curran EM. Sleep disturbance and the effects of extended-release zolpidem during cannabis withdrawal. Drug Alcohol Depend. 2011;117(1):38-44.

59. Lanneau C, Green A, Hirst WD, Wise A, Brown JT, Donnier E, et al. Gabapentin is not a GABAB receptor agonist. Neuropharmacology. 2001;41(8):965-75.

60. Sills GJ. The mechanisms of action of gabapentin and pregabalin. Curr Opin Pharmacol. 2006;6(1):108-13.

61. Almela P, Navarro-Zaragoza J, García-Carmona JA, Mora L, Hidalgo J, Milanés MV, et al. Role of corticotropin-releasing factor (CRF) receptor-1 on the catecholaminergic response to morphine withdrawal in the nucleus accumbens (NAc). PLoS One. 2012;7(10):e47089.

62. Mason BJ, Crean R, Goodell V, Light JM, Quello S, Shadan F, et al. A proof-of-concept randomized controlled study of gabapentin: effects on cannabis use, withdrawal and executive function deficits in cannabis-dependent adults. Neuropsychopharmacology. 2012;37(7):1689-98.

63. Kau KS, Madayag A, Mantsch JR, Grier MD, Abdulhameed O, Baker DA. Blunted cystine-glutamate antiporter function in the nucleus accumbens promotes cocaine-induced drug seeking. Neuroscience. 2008;155(2):530-7.

64. Berk M, Malhi GS, Gray LJ, Dean OM. The promise of Nacetylcysteine in neuropsychiatry. Trends Pharmacol Sci. 2013;34(3):167-77.

65. Gray KM, Carpenter MJ, Baker NL, DeSantis SM, Kryway E, Hartwell KJ, et al. A double-blind randomized controlled trial of $\mathrm{N}$-acetylcysteine in cannabis-dependent adolescents. Am J Psychiatry. 2012;169(8):805-12.

66. Buckley PF. Broad therapeutic uses of atypical antipsychotic medications. Biol Psychiatry. 2001;50(11):912-24.

67. Cohrs S, Rodenbeck A, Guan Z, Pohlmann K, Jordan W, Meier A, et al. Sleep-promoting properties of quetiapine in healthy subjects. Psychopharmacology (Berlin). 2004;174(3):421-9.

68. Cooper ZD, Foltin RW, Hart CL, Vosburg SK, Comer SD, Haney M. A human laboratory study investigating the effects of quetiapine on marijuana withdrawal and relapse in daily marijuana smokers. Addict Biol. 2013;18(6):993-1002.

69. Bowen R, Mcllwrick J, Baetz M, Zhang X. Lithium and marijuana withdrawal. Can J Psychiatry. 2005;50(4):240-1.

70. Winstock AR, Lea T, Copeland J. Lithium carbonate in the management of cannabis withdrawal in humans: an open-label study. $\mathrm{J}$ Psychopharmacol. 2009;23(1):84-93.

71. Cui SS, Bowen RC, Gu GB, Hannesson DK, Yu PH, Zhang X. Prevention of cannabinoid withdrawal syndrome by lithium: involvement of oxytocinergic neuronal activation. J Neurosci. 2001;21(24):9867-76.

72. McRae-Clark AL, Baker NL, Maria MM, Brady KT. Effect of oxytocin on craving and stress response in marijuana-dependent individuals: a pilot study. Psychopharmacology (Berlin). 2013;228(4):623-31.

73. Haney M, Bedi G, Cooper ZD, Glass A, Vosburg SK, Comer SD, et al. Predictors of marijuana relapse in the human laboratory: robust impact of tobacco cigarette smoking status. Biol Psychiatry. 2013;73(3):242-8. 